\title{
ORGANIZAÇÃO ESPACIAL E SUSTENTABILIDADE DE AGROECOSSISTEMAS NO ESTUÁRIO DO RIO SÃO FRANCISCO - BRASIL
}

\section{THE SPACE AND AGROECOSYSTEMS SUSTAINABILITY ORGANIZATION IN ESTUARY RIO SAN FRANCISCO - BRAZIL}

\author{
Cleidinilson Jesus Cunha ${ }^{1}$, José Wellington Carvalho Vilar ${ }^{1}$, Lidriana Souza Pinheiro ${ }^{2}$ \\ ${ }^{1}$ Instituto Federal de Sergipe (IFS), São Cristóvão, SE, Brasil \\ ${ }^{2}$ Universidade Federal do Ceará (UFC), Fortaleza, CE, Brasil
}

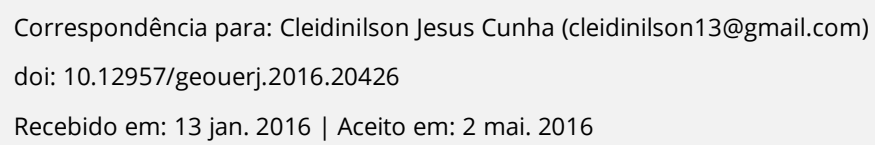

\section{RESUMO}

A construção de barragens e a regularização da vazão têm implicação direta no sistema hidrológico do Baixo São Francisco (BSF), com reflexos nos processos de erosão e sedimentação e na relação homem-natureza. O objetivo do presente artigo é discutir e compreender a organização dos agroecossistemas do estuário do rio São Francisco a partir do estudo de seus componentes e suas interações, estrutura, funcionalidade, inputs e outputs do sistema, além de seus limites territoriais. A avaliação das propriedades dos agroecossistemas, como proposto por Conway (1983 e 1987) e Marten (1988), constitui uma importante ferramenta para a compreensão da interação dos elementos do sistema ambiental do estuário, bem como a identificação e discussão dos impactos na estrutura, funcionalidade e avaliação das propriedades (produtividade, estabilidade e equidade) dos agroecossistemas. A regularização da vazão provocou mudanças na dinâmica ambiental, reduzindo a agrobiodiversidade, comprometendo a sustentabilidade dos agroecossistemas e a oferta de alimentos para a fauna aquática, interferindo no processo de renovação das várzeas e na explotação dos recursos pesqueiros.

Palavras-chave: Sustentabilidade de Agroecossistemas, Geomorfologia Fluvial e Estuário.

\section{ABSTRACT}

The construction of dams and regulating the flow is directly implicated in the hydrological system of the Lower São Francisco (BSF), reflected in the erosion and sedimentation and the man nature relationship. The purpose of this article is to discuss and understand the organization of agro-ecosystems of the São Francisco River estuary from the study of its components and their interactions, structure, functionality, inputs and outputs of the system, beyond its boundaries. The evaluation of the properties of agro-ecosystems as proposed by Conway (1983 and 1987) and Marten (1988), is an important tool for understanding the interaction of environmental estuary system as well as the identification and discussion of impacts on the structure, function and assessment of the properties (productivity, stability and equity) of agroecosystems. The regulation of the flow caused changes in environmental dynamics, reducing agricultural biodiversity, compromising the sustainability of agroecosystems and food supply for aquatic fauna, interfering in the process of renewal of floodplains and exploitation of fish stocks.

Keywords: Sustainable Agroecosystems, Geomorphology River and Estuary.

\section{INTRODUÇÃO}

A estrutura e funcionalidade dos agroecossistemas permitem identificar e avaliar suas propriedades

(CONWAY, 1987; MARTEN, 1988; GLIEESMAN, 2001; D'AGOSTINI, 1999; ALTIERI, 1999;

2004), pois pressupõem melhor compreensão da dinâmica ambiental (HART, 1985) e das mudanças 
inerentes aos sistemas, culminando com o rebatimento na organização socioambiental local (ASTIER et al, 2008).

Por tudo o que encerram em si, os sistemas agrários podem ser reconhecidos como modelos de representação que facilitam a compreensão de espacialidades permitindo alcançar fatores que interferem em sua organização e que ocorrem em um determinado ecossistema (OLIVEIRA et al, 2009).

Entre Sergipe e Alagoas, no estuário do rio São Francisco, organizam-se sistemas produtivos em ecossistemas baseados na exploração de recursos naturais, a partir da atividade pesqueira e da tradicional captura de caranguejo, bem como em atividades econômicas introduzidas mais recentemente, como a agricultura irrigada, piscicultura e carcinicultura, que determinaram impactos substanciais na organização do espaço local.

A partir da identificação desses sistemas produtivos é possível estabelecer as características básicas dos componentes dos agroecossistemas, subsistemas, estrutura e função, na perspectiva de discutir a (in)sustentabilidade da apropriação e uso dos recursos naturais da zona de mistura e do seu entorno, em função de atividades agrícolas com diferentes níveis de uso de tecnologias.

Bianchi et al (2006) afirmam que, de uma forma geral, as diversas conceituações de agroecossistemas variam conforme os autores, mas um ponto pacífico parece se associar a sua origem: o agroecossistema é criado quando a manipulação humana e a alteração de um ecossistema dão lugar ao propósito do estabelecimento da agropecuária, produzindo diversas mudanças na estrutura e funcionamento do ecossistema natural.

Os agroecossistemas se diferenciam dos demais ecossistemas por apresentarem fluxo de energia e ciclagem de nutrientes mais abertos, por mostrarem redução da biodiversidade, diminuição dos níveis tróficos e menor capacidade de autorregulação do sistema. Cabe ressaltar que os agroecossistemas 
podem apresentar elevado nível de tecnificação ou ainda podem ser tradicionais. Sobre os agroecossistemas tradicionais, Altieri (2004) afirma que há um interesse geral em reintegrar uma racionalidade ecológica à produção agrícola e em fazer ajustes mais abrangentes na agricultura convencional, para torná-la ambiental, social e economicamente viável e compatível.

O objetivo do presente artigo é discutir e compreender a organização dos agroecossistemas do estuário do rio São Francisco a partir do estudo de seus componentes e interações, a estrutura, funcionalidade, inputs e outputs do sistema, além de seus limites territoriais.

\section{Metodologia}

A área de estudo compreende o estuário do rio São Francisco e seu entorno, incorporando os municípios de Piaçabuçu e Penedo, no Estado de Alagoas, e os municípios de Brejo Grande, Ilha das Flores e Neópolis, no Estado de Sergipe.

A complexidade de fatores envolve a definição e caracterização, bem como a estrutura, funcionalidade e propriedades dos agroecossistemas no estuário do rio São Francisco, mediante a metodologia apresentada por Marten (1988) e Conway (1983; 1987). Numa perspectiva sistêmica, pretende-se, a partir das transformações recentes ocasionadas pela ação antrópica, compreender a estrutura e 0 funcionamento dos agroecossistemas locais.

O estudo das propriedades dos agroecossistemas aplicar-se-á às atividades agrícolas desenvolvidas no estuário e no seu entorno, em diversas estruturas agrárias locais, bem como às atividades de pesca e de captura de crustáceos ocorridas no estuário, nos municípios acima referenciados.

As propriedades dos agroecossistemas são atributos que podem ser utilizados na identificação, caracterização e avaliação das unidades de produção. Cabe, portanto, destacar que os usos das propriedades auxiliam na compreensão da estrutura e na funcionalidade dos agroecossistemas 
(CUNHA e HOLANDA, 2007). As propriedades dos agroecossistemas não devem ser analisadas e discutidas de forma isolada, mas compreendidas a partir de uma complexidade que permita a integração das referidas propriedades à constituição da estrutura e funcionalidade dos agroecossistemas.

Conway (1987) sugere que sejam utilizadas quatro propriedades primárias dos agroecossistemas: produtividade, estabilidade, sustentabilidade e equidade. As três primeiras correspondem às propriedades dos ecossistemas naturais, e a principal distinção entre elas é a de que cada uma é definida em termos de produção do sistema e, portanto, podem ser medidas tanto em termos biológicos quanto socioeconômicos. Vale ressaltar que a quarta propriedade, equidade, não tem correlação com os sistemas ecológicos.

A produtividade do agroecossistema é definida por Conway (1987) como a produção de um determinado produto por unidade de recurso que entra numa área. Algumas medidas comuns de produtividade são o rendimento por hectare ou a produção total de comida e serviços de família ou de uma nação.

Segundo Marten (1988), a estabilidade diz respeito às várias flutuações que pode sofrer um agroecossistema, como variações de preços no mercado e sua capacidade de manter a produtividade em longo prazo. Como a estabilidade deriva da produtividade, ela é multidimensional, assim como a produtividade o é. Um determinado agroecossistema pode ser relativamente estável, se consideradas algumas medidas de produtividade, e instável com relação a outras.

A sustentabilidade, para Conway (1987), é definida como a habilidade que tem um agroecossistema de manter sua produtividade quando submetido a um grande distúrbio. A perturbação pode ser causada por uma pressão intensiva, capaz de gerar efeitos acumulativos, como salinidade, toxidade, erosão, declínio da demanda do mercado, seca e enchentes. 
Os dados hidrológicos foram obtidos na Companhia Hidrelétrica do São Francisco (CHESF), a partir do sistema de controle e gerenciamento de dados hidrológicos, bem como no Sistema de Informações Hidrológicas (SIH) da Agência Nacional das Águas (ANA). As estações fluviométricas (Traipu-AL e Propriá-SE) utilizadas para leitura e interpretação foram aquelas situadas a jusante da Usina Hidrelétrica de Xingó.

As séries históricas referem-se ao período anterior e posterior à construção da UHE (Usina Hidrelétrica) Xingó, com dados de vazões normais, restrição, médias diárias (07h e 17h) mensais e anuais máximas e mínimas. Também foram coletados dados relativos ao comportamento dos reservatórios de Xingó e à montante, tendo em vista a capacidade de retenção de águas do canal fluvial das barragens de Sobradinho e Itaparica (BA) e o caráter sazonal de descargas do rio São Francisco no seu baixo curso e, em especial, no estuário.

Entre os vários órgãos públicos de importante contribuição para o trabalho estão: Instituto Brasileiro de Geografia e Estatística (IBGE), Agência Nacional de Águas (ANA), Agência Nacional de Energia Elétrica (ANEEL), Companhia Hidrelétrica do São Francisco (CHESF), Companhia de Desenvolvimento dos Vales do São Francisco e Parnaíba (CODEVASF), Fundação Apolônio Sales (FADURPE) e o Instituto Brasileiro do Meio Ambiente e dos Recursos Naturais Renováveis (IBAMA). Os trabalhos científicos que algumas universidades desenvolveram ou desenvolvem na área de estudo também foram alvos de análise e interpretação. Destacam-se, entre elas, as seguintes instituições: UFS, UFAL, UFBA, UECE, UFC, entre outras.

No Estado de Sergipe, merecem destaque a Secretaria de Recursos Hídricos e Meio Ambiente (SEMARH), a Administração Estadual do Meio Ambiente (ADEMA) e a Secretaria de Estado do Planejamento, Orçamento e Gestão (SEPLAG). Já no Estado de Alagoas, são destacadas a Secretaria do Meio Ambiente e Recursos Hídricos (SEMARH) e a Secretaria de Estado do Planejamento e do Desenvolvimento Econômico (SEPLAN). Do ponto de vista municipal, esse trabalho também utilizou 
dados e informações das prefeituras de Brejo Grande e Ilha das Flores, no Estado de Sergipe, e Piaçabuçu e Penedo, no Estado de Alagoas.

Os dados primários foram coletados nas campanhas de campo, a partir de entrevista e questionário previamente elaborado e aplicado de forma aleatória, objetivando averiguar a organização dos sistemas produtivos e a importância do sistema ambiental para a comunidade estuarina, bem como as condições socioeconômicas e culturais da população da área em foco, além da percepção desses atores quanto aos problemas dos sistemas agrícolas e agroecossistemas locais.

As campanhas de campo ocorreram no segundo semestre de 2013 e primeiro semestre de 2014, utilizando tanto a via fluvial em embarcações de pequeno porte, quanto a via terrestre a partir das rodovias estaduais (AL-225, SE-200 e SE-204) e vicinais que margeiam o rio São Francisco, respeitando os limites dos municípios de Brejo Grande, Ilha das Flores e Neópolis, no Estado de Sergipe e os municípios de Piaçabuçu e Penedo, no Estado de Alagoas. Os municípios citados estão diretamente integrados, socioambientalmente, à dinâmica estuarina (zona de mistura) e ao seu entorno.

Nas visitas de campo foram utilizados procedimentos e técnicas de pesquisa que possibilitassem maiores informações sobre o objeto de estudo. Na ocasião, foram desenvolvidas técnicas como a observação direta, processos de comunicação direta (entrevistas livres) com pescadores, agricultores, gestores de associações e técnicos da CODEVASF.

\section{Resultados e discussão}

\section{As mudanças na dinâmica fluvial}

Como inputs importantes para o agroecossistema do estuário e para o presente trabalho, destaca-se, inicialmente, a dinâmica fluvial que permite as condições ambientais necessárias, juntamente com a dinâmica oceânica, para a manutenção do estoque de pesca e desenvolvimento da diversidade de atividades econômicas. As alterações do sistema fluvial, a partir da regularização da vazão, promovem 
mudanças no fluxo de vazão e de sedimentos (CUNHA, 2011), causando a reorganização dos sistemas produtivos.

Segundo Conway (1987), cada combinação possível de entrada e saída pode ser considerada como medida de eficiência da produção quando dois ou mais agroecossistemas são comparados, e essas comparações podem ser feitas entre agroecossistemas de diferentes tipos.

Desde abril de 2013 que várias resoluções da ANA se sucederam, com o intuito de estabelecer descargas mínimas defluentes nos reservatórios, inicialmente de $1300 \mathrm{~m}^{3} / \mathrm{s}$ para $1100 \mathrm{~m}^{3} / \mathrm{s}$ e, posteriormente, estabelecendo outras vazões de restrição temporárias ainda menores, ficando o acompanhamento de controle das defluências por parte das estações fluviométricas de Juazeiro (ANA 48020000) e Propriá (ANA 49705000). Mais recentemente, a partir da Resolução 1.492, publicada no Diário Oficial da União de 21/12/2015, a vazão de restrição seria alterada de $900 \mathrm{~m}^{3} / \mathrm{s}$ para 800 $\mathrm{m}^{3} / \mathrm{s}$, contribuindo, assim, de forma decisiva, para a ampliação dos impactos na dinâmica ambiental e, por conseguinte, na organização dos agroecossistemas do Baixo São Francisco.

Os barramentos construídos a montante do estuário promoveram a retenção de sedimentos, fato que se intensificou com a construção da UHE Xingó. Isso implicou na redução da oferta de alimentos (fitoplâncton e zooplâncton) para a fauna dos manguezais.

Para Silva et al (2010), o rio São Francisco tem apresentado, ao longo dos anos, uma diminuição da concentração de material em suspensão entre suas regiões fisiográficas. O rio São Francisco vem sofrendo, no decorrer dos anos, uma drástica redução da concentração e da carga de sedimentos abaixo da Usina Hidrelétrica de Xingó. Segundo o referido autor, a carga de sedimentos passou de 69 x 106 em 1975 para 2,62 x 106 em 2007, sofrendo, assim, uma brusca queda da carga de sedimentos transportados pelo rio. 
Ainda sobre a redução da carga de sedimentos, o estudo de Oliveira et al (2003) concluiu que existe uma redução drástica na alimentação do estuário do rio São Francisco. O aporte sólido não está sendo suficiente para manter a sua foz em equilíbrio, resultando em uma acelerada erosão da sua margem direita. O estuário do rio São Francisco deverá se transformar, a curto prazo, em uma foz protegida por um cordão litorâneo formado por areias de praia transportadas pela deriva litorânea gerada pelas ondas.

Além do comprometimento da oferta de alimentos para a fauna do estuário, é fundamental referenciar outra força ou pressão exercida sobre os manguezais, principal área de reprodução e captura de caranguejo, que diz respeito ao acentuado processo de erosão, junto a praia do Cabeço, o que compromete a manutenção do estoque de pesca nesse ecossistema. A figura 1 identifica e classifica os terrenos próximos a foz a partir da Era geológica de formação dos mesmos; pode-se observar, mediante a disposição do manguezal no sentido Norte/Sul, área de intenso processo erosivo.

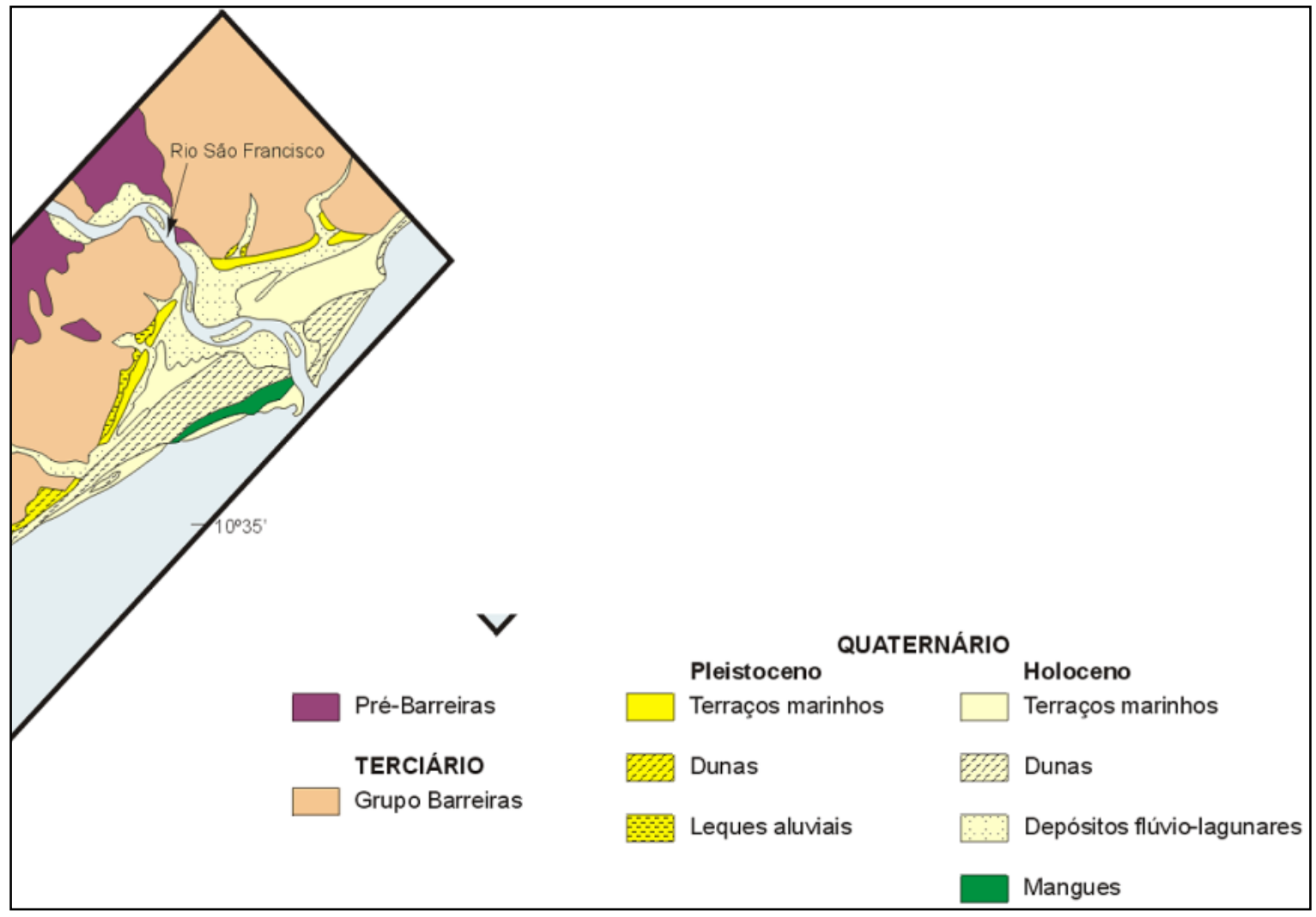

Figura 1. Mapa Geológico simplificado do litoral norte de Sergipe e sul de Alagoas. Fonte: Adaptado de Amâncio (2001). 
No estuário do rio São Francisco, em área de manguezais, os crustáceos, moluscos, peixes e o meio abiótico constituem componentes singulares, pois organizam cadeias produtivas que podem sofrer flutuações devido perturbações ao sistema. A interação equilibrada e sustentável entre os componentes do sistema é fundamental para o uso dos recursos disponíveis no manguezal, pois os níveis de produtividade interferem diretamente na estabilidade dos agroecossistemas.

No estuário, o agroecossistema apresenta-se com componentes bióticos, representados pela população de seres vivos, em especial destaque para a fauna (peixes, crustáceos e moluscos), pela diversidade de vegetação, por micro-organismos, etc. Os mesmos interagem com os componentes abióticos, como o solo dos manguezais, das várzeas, das planícies aluvionais, devido ao fluxo d'água promovido pela variação das marés e às vazões fluviais do São Francisco, entre outros fatores.

Assim se pode definir subsistemas inerentes aos fatores abióticos, subsistemas solo e água, como os de maior significância para a distribuição geográfica dos agroecossistemas do estuário. O subsistema solo é responsável por estabelecer processos bióticos importantes como a atividade de micro-organismos, bem como promover os processos biogeoquímicos fundamentais para a sustentabilidade ecológica e, por conseguinte, econômica.

O subsistema água caracteriza-se como resultante das dinâmicas fluvial e oceânica, em função da vazão e marés, respectivamente. O contato das águas fluviais do São Francisco com as águas marinhas constitui condições peculiares para o desenvolvimento da fauna aquática, isto é, forma uma área de suma importância para a reprodução de várias espécies da fauna, mantendo relações intrínsecas com o subsistema vegetação.

O controle de vazões e regularização, a partir da UHE Xingó, promoveu uma redução acentuada das lagoas marginais, devido à ausência das cheias naturais que, em período de enchentes eram abastecidas por águas e sedimentos que serviam de alimentos para a fauna estuarina, bem como 
interferia no ciclo natural de reprodução da fauna, e ainda extinguiu a agricultura tradicional de vazante realizada pelos ribeirinhos.

Salienta-se que a regularização dos fluxos fluviais promoveu também erosão marginal (CUNHA, 2011 e FONTES, 2002), representando fator de pressão ou impacto nas atividades agrícolas desenvolvidas no baixo São Francisco, como a destruição da estrada e do dique de proteção no Perímetro Irrigado Cotinguiba/Pindoba, onde o cenário se apresenta bastante crítico.

Ainda sobre os impactos causados ao subsistema água, pode-se mencionar que o controle de vazão fluvial e os diversos problemas de ordem ambiental do rio São Francisco, têm trazido problemas às estações de captação de água em terra, pois, devido à redução de vazão, atualmente de restrição, temse optado pelas estações de captação flutuantes. As entrevistas realizadas com técnicos dos perímetros irrigados da CODEVASF e técnicos de companhias de abastecimento de água em Alagoas (CASAL) e Sergipe (DESO) confirmaram tal problemática quanto à captação de água, fato também comprovado em visitas de campo.

Ainda sobre a água, é importante considerar o elevado nível de concentração de agroquímicos que são lançados no rio em áreas dos perímetros irrigados para a rizicultura. As áreas de drenagem dos perímetros enviam para o curso fluvial elevada carga de agroquímicos sem que o mesmo seja tratado adequadamente.

Na figura 2, observa-se a localização do canal de drenagem dos lotes de rizicultura do perímetro irrigado de Betume para o leito principal do rio. Em visita de campo e entrevista com técnicos do perímetro, foi constatado que não há tratamento para esse efluente e que, sobre os agroquímicos, é evidenciado para o produtor a necessidade do "uso racional" dos produtos, a partir de orientação técnica e de cursos de capacitação. 


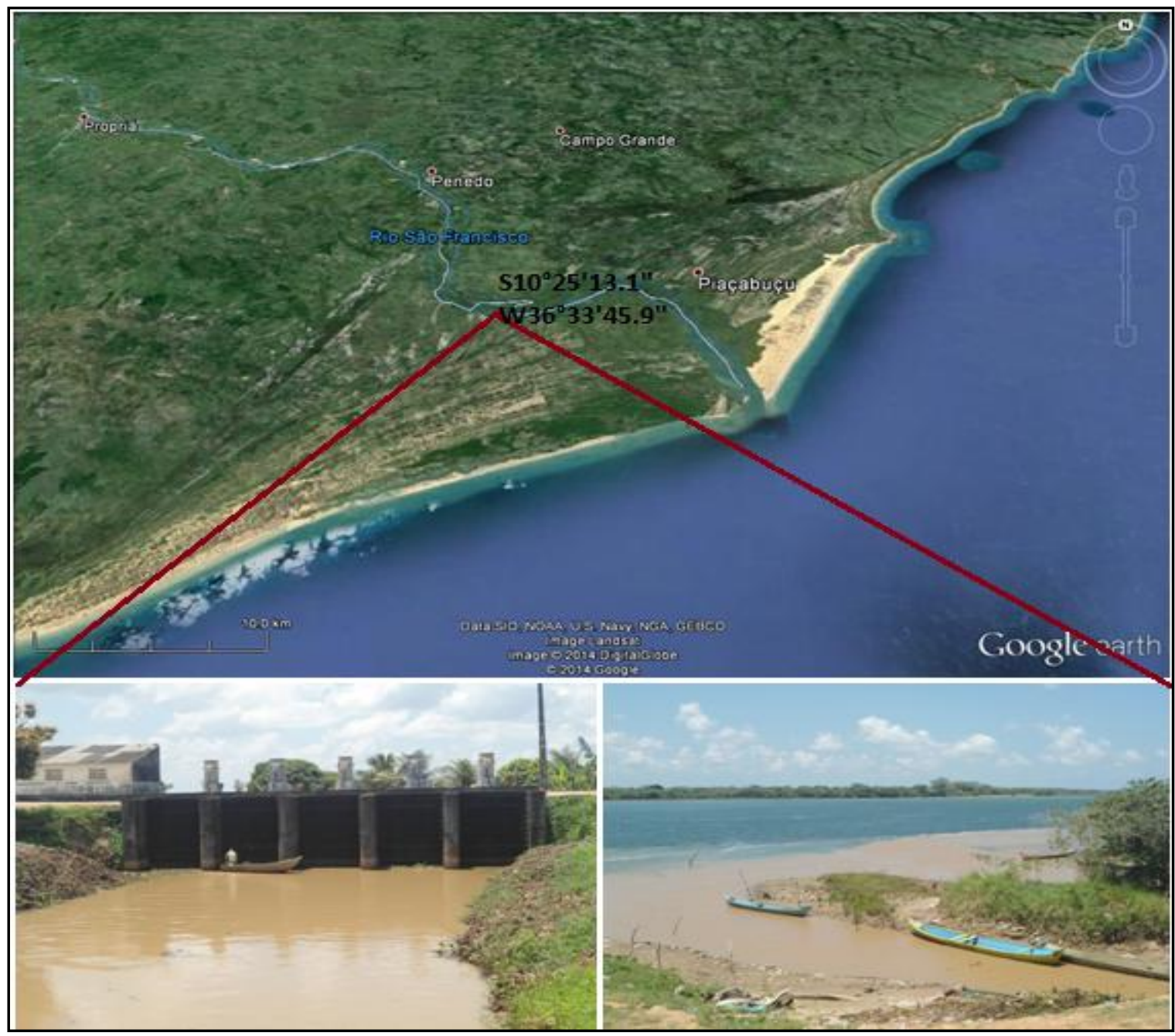

Figura 2. Primeiro plano, localização do canal de drenagem do perímetro irrigado de Betume em Ilha das

Flores/SE. No plano inferior, imagens do canal de drenagem com visualização da parte interna e do lançamento no leito principal do rio, respectivamente. Elaboração e crédito das fotos: Autor, 2014.

\section{Limites físico, espacial e temporal dos agroecossistemas.}

Na definição de seus limites, identifica-se uma espacialidade arbitrária, devido à complexidade interna e à rede de conexões que se estabelecem nos agroecossistemas. 0 sistema estuarino revela-se como complexo e aberto, tendo em vista as interações entre os componentes inerentes ao sistema e aos elementos externos a ele. Vários são os elementos e fatores que interferem na organização dos agroecossistemas, que se situam "fora" do estuário, mas que têm efeitos determinantes na sua estrutura e funcionalidade. 
A amplitude de conexão dos fatores vai além do limite físico do estuário, pois esse ambiente resulta da interação e complexidade de vários elementos. No entanto, é possível identificar um limite físico basilar para $0(\mathrm{~s})$ agroecossistema(s): o estuário. Já o limite espacial, definido como arbitrário, refere-se à rede de interações entre o estuário e demais espaços adjacentes que contribuem com a sua configuração, como aqueles situados a montante (barragens, sedimentos, vazão, etc.) e a jusante, como a dinâmica oceânica (marés, ventos, corrente marítima, etc.), além das áreas vizinhas, como as propriedades rurais, as áreas urbanas, o mercado, etc.

É possível ainda estabelecer um limite cronológico para o agroecossistema do estuário, por meio da regularização da vazão fluvial, das marés, dos períodos diferenciados ao longo do ano de maior e menor produção de pescados e do período de defeso do caranguejo, que estabelecem periodicidade para a exploração dos recursos do estuário.

Os limites cronológicos em agroecossistemas tradicionais são determinadas pelos períodos de maior produção pesqueira, bem como pelo estabelecimento do período de defeso que ocorre a partir de novembro e segue por quatro meses no rio e seis meses nas lagoas marginais. O período é definido em virtude da reprodução dos peixes que se relaciona com a dinâmica fluvial e ao regime de vazões.

\section{Estrutura e funcionalidade dos agroecossistemas}

Considerando a estrutura e função dos agroecossistemas no Baixo São Francisco, cabe explicitar algumas características inerentes à configuração dos mesmos, tendo em vista que é possível não apenas identificar as cadeias produtivas construídas historicamente e as recentemente implantadas com a expansão do capital e da necessidade de mercado, como a introdução da carcinicultura e dos perímetros irrigados introduzidos pela CODEVASF, bem como as técnicas de manejo e as ações públicas em vários níveis. 
Nesse estudo é básico o entendimento dos agroecossistemas como um sistema aberto, sujeito a instabilidade entre seus componentes e outros sistemas. Assim, não se pode perder de vista as várias interações entre o regional e o local, bem como a complexidade de elementos que interagem com a pesca artesanal, com a captura de caranguejo e com as demais atividades, como a rizicultura e a carcinicultura, além dos projetos ou ações públicas de desenvolvimento, entre outros.

A estrutura está organizada a partir de arranjos temporais, haja vista que a pesca e captura do caranguejo obedecem a ciclos naturais, como o das marés, ou ainda a períodos de defeso, constituindose em importantes elementos no Plano de Manejo a reposição e manutenção dos estoques naturais. Acrescenta-se o fato de que as atividades agrícolas dos perímetros irrigados apesar de não seguirem a mesma abordagem quanto aos ciclos naturais, passam por restrição quanto ao uso de água devido a redução dos níveis de vazão.

A funcionalidade dos agroecossistemas está condicionada aos inputs e output, pois o sistema natural é impactado, e os fluxos de energia são modificados e introduzidos para maximizar a produção e produtividade. Ela também está condicionada às dinâmicas oceânicas e fluviais que oferecem as bases naturais para a estrutura e funcionalidade dos sistemas produtivos (extrativistas ou agrícolas). Somam-se aos inputs, a tecnologia, o sistema de informações e o Plano de Manejo. O processamento dessas entradas no agroecossistema vai permitir a possibilidade de outputs ao sistema representado pela produção de peixe, caranguejo, gêneros agrícolas, etc.

Outra característica do subsistema animal trata das políticas de controle do uso de recursos naturais com a introdução de sistemas de manejo. Assim, ocorre a necessidade de um Plano de Manejo específico para elementos desse subsistema que se consolida com o estabelecimento do "defeso" que proíbe, por lei, a pesca ou a captura de caranguejo em períodos pré-determinados. Com isso, se estabelece um componente ou indicador que prima pela manutenção dos estoques de pesca, já que minimiza a explotação dos recursos pesqueiros e as consequências das alterações promovidas pela regularização da vazão para os estoques de pesca e de caranguejo no estuário do rio São Francisco. 
As informações que entram no sistema podem ser originadas de duas fontes principais: das informações que se associam aos empreendimentos recentes de carcinicultura e das informações que ocorrem entre os pescadores artesanais e catadores de caranguejo, os quais se encarregam de reproduzir, a partir da família, o conhecimento tradicional oral acumulado e repassado de geração a geração.

\section{Organização espacial dos agroecossistemas modernos e tradicionais}

Para o estuário em estudo, vale ressaltar a relativa diferenciação espacial entre os agroecossistemas tradicionais, representados por atividades extrativistas ou pequenas propriedades agrícolas com produção direcionada para o agricultor e para o mercado local, e os agroecossistemas com maior aplicação de tecnologia e capitais, geralmente destinando sua produção ao mercado regional ou nacional, como é o caso dos carcinicultores e da agricultura desenvolvida nos perímetros irrigados.

Destaca-se que nos perímetros irrigados, coordenados pela CODEVASF, predomina a força de trabalho familiar, com contrato realizado com mão de obra externa apenas nos períodos de maior necessidade, com dados referentes aos perímetros do Betume e Cotinguiba/Pindoba, ambos localizados no entorno do estuário.

No vale do São Francisco, foram implantados vários projetos para produção agrícola irrigada e piscicultura. Mais especificamente no Baixo São Francisco, a situação não é diferente, pois vários projetos foram desenvolvidos e outros estão em implantação ou em estudo. Os projetos mais importantes foram planejados e são administrados pela CODEVASF, como o ITIÚBA (município de Porto Real do Colégio/AL), BOACICA (municípios de Igreja Nova e Penedo/AL), MARITUBA (município de Penedo/AL), JACARÉ-CURITUBA (municípios de Canindé do São Francisco e Poço Redondo/SE), BETUME (municípios de Neópolis, Ilha das Flores e Pacatuba/SE), COTINGUIBA/PINDOBA (municípios de Japoatã, Neópolis e Propriá/ SE) e PROPRIÁ (Municípios de Cedro de São João, Propriá e Telha/SE). 
Apesar dos problemas relacionados ao curso fluvial, no tocante à regularização e redução significativa de vazão nas últimas décadas, em especial no período posterior à construção da UHE Xingó, com diminuição nos últimos anos da vazão média de restrição de $1300 \mathrm{~m}^{3} / \mathrm{s}$ para $1100 \mathrm{~m}^{3} / \mathrm{s}$, e a possibilidade de nova vazão (menor) de restrição, novos projetos são implantados com a finalidade de uso múltiplo das águas do São Francisco. Os projetos existentes são ampliados para aumentar a produção e atendimento ao mercado, necessitando de maior volume de água para a demanda dos perímetros irrigados, bem como para o abastecimento urbano, devido ao crescimento das cidades.

No entorno do estuário, em antigas áreas de várzeas que originalmente eram inundadas naturalmente em período de cheias do rio, funcionam os perímetros irrigados que se dedicam, principalmente, à produção de arroz e que utilizam sistemas de bombeamento ou de aspersão convencional.

Apesar das dificuldades nas estações de captação de água, a redução da vazão não interferiu no rendimento médio da produção de arroz, como demonstra a tabela 1. Ao contrário, segundo informações de técnicos da CODEVASF, a produção de arroz nos perímetros tem aumentado com o decorrer dos anos. Esse fato revela que a redução da vazão não significou necessariamente a redução da produção, pois a alternativa encontrada foi promover o uso de estações de captação flutuante.

\begin{tabular}{l|c|c|l}
\hline \multicolumn{1}{c|}{ Perímetro } & Área ocupada (ha) & $\begin{array}{c}\text { Produção } \\
\text { total (t) }\end{array}$ & \multicolumn{1}{|c}{ Principais produtos } \\
\hline Boacica (AL) & 2.762 ha & $55.016 \mathrm{t}$ & $\begin{array}{l}\text { Arroz (64\%); Cana-de-açúcar } \\
(36 \%)\end{array}$ \\
\hline Marituba (AL) & 4.200 ha & S/d & $\begin{array}{l}\text { Banana, cana-de-açúcar, coco, goiaba, } \\
\text { inhame, limão e pinha. Peixe, } \\
\text { camarão e pecuária }\end{array}$ \\
\hline Betume (SE) & 2.860 ha & $10.762 \mathrm{t}$ & Arroz \\
\hline Cotinguiba/Pindoba (SE) & 2.232 ha & $12.309 \mathrm{t}$ & $\begin{array}{l}\text { Arroz (70\%) } \\
\text { Milho (22\%) }\end{array}$ \\
\hline
\end{tabular}

Tabela 1. Principais perímetros irrigados no entorno do estuário do rio São Francisco. Fonte: Dados da CODEVASF (2010). Organização: Autor, 2014. 
Mesmo com o aumento da produção nos perímetros com reduzida vazão do rio, os agricultores dos lotes do Cotinguiba/Pindoba consideram insuficientes os serviços de irrigação $(62,5 \%)$ e drenagem $(48,3 \%)$ oferecidos pela CODEVASF; enquanto que, no perímetro do Betume essa insatisfação do produtor em relação à irrigação é de $42,3 \%$ e, em relação à drenagem, é de $55,8 \%$, segundo diagnóstico de 2010, realizado pelo órgão nos perímetros irrigados citados.

\section{Propriedades dos agroecossistemas do estuário}

No contexto da produtividade, percebe-se que o agroecossistema de rizicultura irrigada se apresenta com níveis elevados de produção e produtividade. Mas, quando se confronta com outras propriedades, como a sustentabilidade e estabilidade, nota-se que o sistema de produção é avaliado como insustentável a longo prazo, pois não considera os problemas oriundos das mudanças do sistema fluvial, como a descarga líquida e de material particulado em suspensão.

Os trabalhos de Conway (1987) e Marten (1988) confirmam que a produtividade se mantém constante mesmo diante de pequenos distúrbios ou flutuações, e que se pode admitir a presença de um novo atributo ao agroecossistema, que é a sua estabilidade.

Quando da avaliação da equidade, não se considera o uso sustentável e coletivo do sistema fluvial, pois visa exclusivamente a atender a demanda local de produção rizícola, desprezando a compreensão do uso sustentável e coletivo dos recursos, como a importância das águas fluviais para os pescadores, catadores de caranguejo e a navegação.

Mesmo diante dos problemas ambientais do rio São Francisco, quanto ao fluxo de vazão do canal fluvial com frequentes reduções da vazão de restrição, o governo brasileiro anunciou, no segundo semestre de 2012, o Programa Mais Irrigação, que pretende ampliar a produção agrícola irrigada, principalmente na bacia hidrográfica do São Francisco. Esse programa receberá investimento de três bilhões do governo federal e 7 bilhões de reais da iniciativa privada (CODEVASF, 2012). 
Parte desse recurso será investida na revitalização e ampliação de perímetros irrigados no Baixo São Francisco, a exemplo dos perímetros de Betume e Cotinguiba/Pindoba, em Sergipe, e Boacica e Marituba, no estado de Alagoas, todos situados na zona estuarina. O modelo adotado na apropriação e uso dos recursos do estuário, por parte de programas oficiais, não têm levado em conta os limites de intervenção no ambiente estuarino e no seu entorno, o que provoca forte instabilidade ao sistema, a médio e longo prazo.

Diferentemente dos sistemas produtivos mais modernos, nos agroecossistemas tradicionais do estuário, observam-se baixos níveis de produtividade, como aqueles proporcionados pela atividade pesqueira e captura de caranguejo, decorrentes da exploração excessiva dos recursos pesqueiros, não respeitando os limites da base dos recursos naturais, bem como resultantes das alterações ambientais ocorridas na base ecológica, trazendo perturbações ao sistema e interferindo no estoque pesqueiro.

A instabilidade do sistema ecológico no estuário do rio São Francisco aponta para a redução da captura de caranguejo-uçá pela comunidade local, o que tem proporcionado barreiras à constituição da estabilidade, sustentabilidade e da equidade desse agroecossistema, já que, em função das perturbações ou distorções ocorridas no sistema, a produtividade não se manteve ao longo do tempo.

A partir dos elementos constituintes dos agroecossistemas, assim como de sua estrutura e funcionalidade, retrata-se a rede de fluxos de materiais e energia, como demonstrados na figura 3 , onde se observa a diferenciação entre os subsistemas que compõem os agroecossistemas tradicionais, representados pela pesca e captura de caranguejo, e aqueles mais modernos, como o sistema de rizicultura que envolve maior aplicação de insumos externos e capitais, bem como de maior impacto ao ambiente estuarino. 


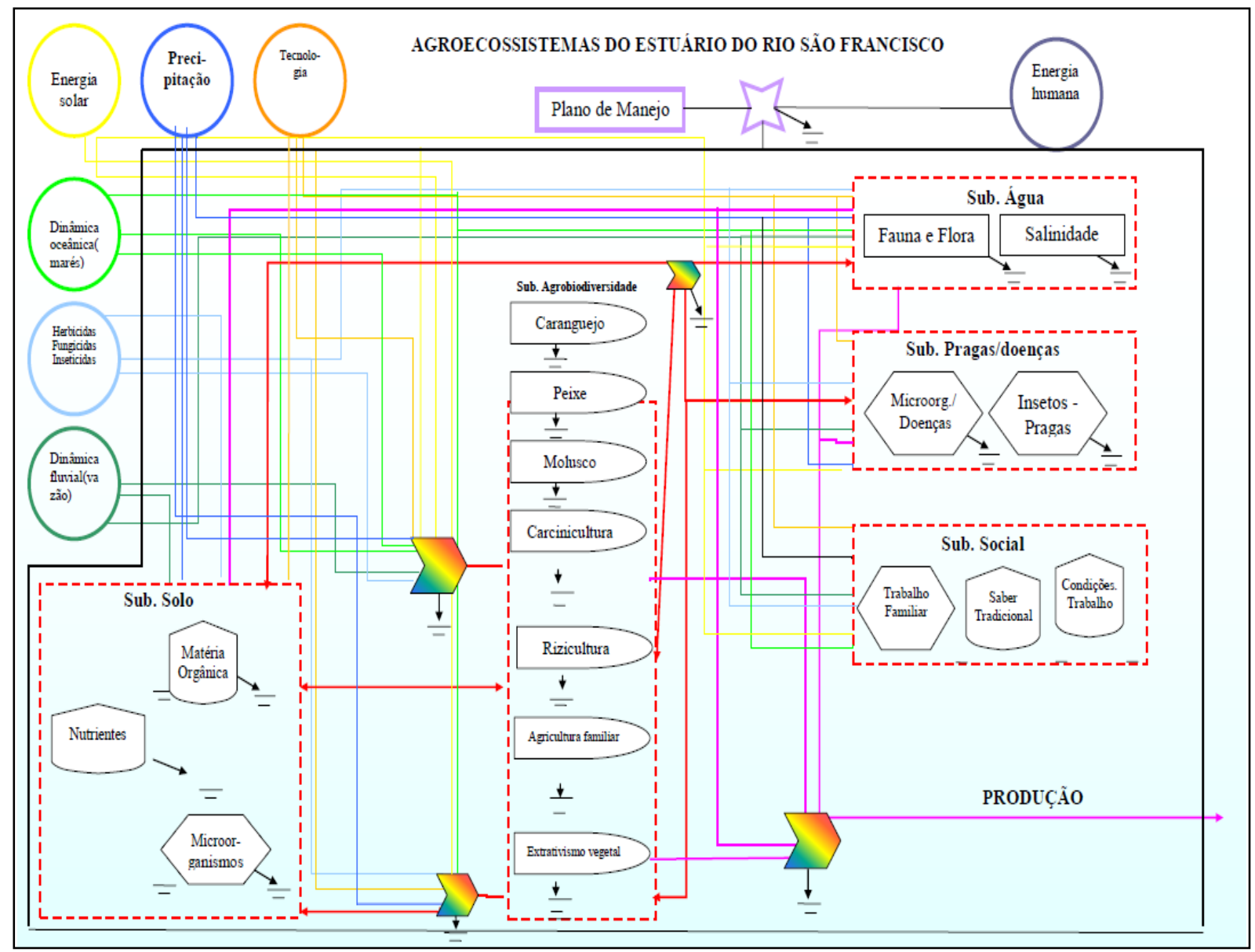

Figura 3. Estrutura organizacional dos agroecossistemas do estuário do rio São Francisco.

Elaboração: Autor, 2014.

Ocorre, assim, uma maior dependência dos agroecossistemas tradicionais em relação aos elementos naturais do estuário, tendo em vista a relação direta e inexorável entre a pesca e a captura de caranguejo, como a dinâmica ambiental estuarina. Esse fato se deve à forte dependência dos ribeirinhos em relação à dinâmica ambiental e ao quanto são afetados pelas mudanças ocasionadas pela construção de barragens e a regularização da vazão, proporcionando dificuldades quanto à manutenção dos estoques de pesca e à extinção da rizicultura de vazante, devido à falta de cheias.

Diante do exposto, pode-se observar, a partir da figura 4, que os ribeirinhos condicionam a queda na produção de pescados, especialmente, à exploração do uso dos recursos do estuário, bem como aos fatores associados à dinâmica fluvial, isto é, às modificações do ecossistema devido ao controle do fluxo hidrossedimentológico, a partir da construção de barragens, com destaque para a UHE Xingó. 


\section{Causas para redução de pescados(\%)}

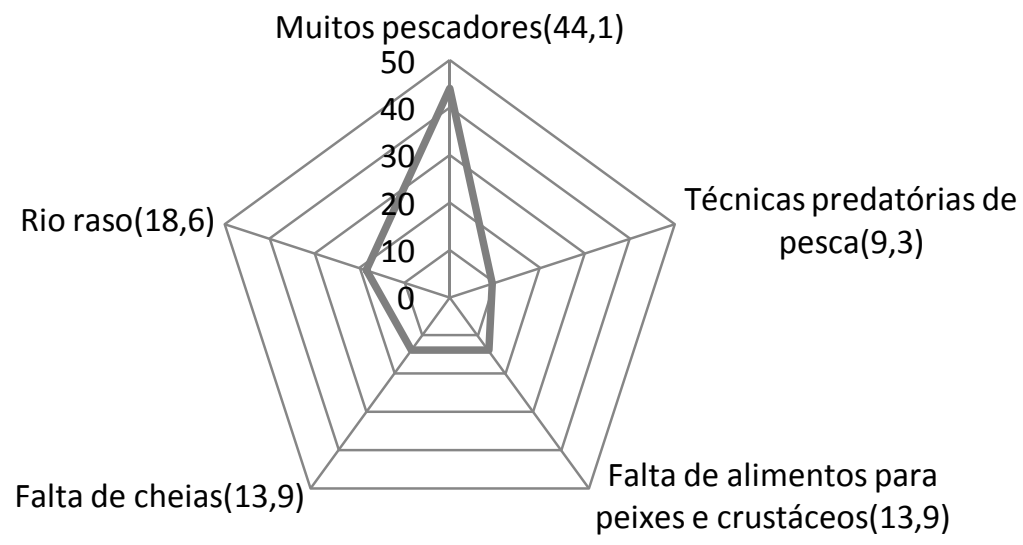

Figura 4. Fatores que contribuem para a redução de pescados em agroecossistemas tradicionais no estuário do rio São Francisco, segundo os ribeirinhos. Fonte: Trabalho de campo, 2014.

A população ribeirinha, inserida nos agroecossistemas tradicionais, dependia, historicamente, das cheias do rio e da carga de sedimentos que era, em parte, depositada nas lagoas marginais e que serviam como verdadeiros "berçários" para a fauna e ainda permitiam a sua utilização para a rizicultura realizada por pequenos produtores com uso intenso de força de trabalho feminina, tendo em vista os cuidados manuais que outrora ocorriam nos arrozais.

\section{CONSIDERAÇÕES FINAIS}

A regularização da vazão do rio São Francisco, diante da construção de barragens e da introdução de empreendimentos que exigem grande aplicação de capital, tem promovido mudanças na dinâmica ambiental e nos ecossistemas modificados para a produção que, por sua vez, tem gerado impactos na organização produtiva e social dos atores sociais do estuário, marginalizando as formas tradicionais de exploração dos recursos pesqueiros, a diversidade sociocultural e os conhecimentos construídos, historicamente, pela população local. 
As mudanças que se processam ao longo da bacia de drenagem têm um papel decisivo no que se refere às alterações da dinâmica ambiental do estuário, e estas remetem a reestruturações no tempo e no espaço, pois incidem em todo sistema produtivo da pesca e da agricultura de base familiar, nas relações do pescador e agricultor, bem como na manutenção e reprodução social da família.

O Baixo São Francisco tem sido objeto de um conjunto de ações que afetou o complexo ambiental, e este, por sua vez, alterou os fluxos energéticos, a ciclagem de nutrientes, constituindo-se, assim, em ambientes instáveis e insustentáveis que determinam alterações nos estoques pesqueiros, interferindo na produtividade da pesca, no estuário e comprometendo as condições de vida dos atores sociais.

O comprometimento do sistema ambiental reflete-se na renda gerada pelos produtores em agroecossistemas tradicionais do estuário, à medida que as mudanças do fluxo fluvial interferiram na oferta de alimentos para a fauna aquática, na formação e renovação das várzeas, provocando não somente a redução de oferta do pescado, mas também aumentando a pressão sobre o ecossistema em virtude do maior número de pescadores e catadores, ou ainda, causando o êxodo rural.

\section{REFERÊNCIAS}

ALTIERI, Miguel. Agroecologia: bases científicas para uma agricultura sustentável. Editorial Nordan-Comunidad, 1999. Montevidéu.

. Agroecologia: a dinâmica produtiva da agricultura sustentável. 4. ed. Porto Alegre: Editora da UFRGS,

2004.

AMÂNCIO, Suely Gleyde. Influência da evolução costeira holocênica na ocupação da costa do estado de Sergipe por Grupos Sambaquieiros. Dissertação de Mestrado. UFBA, 2001.

ASTIER, M. et al. El marco de evaluación MESMIS y su aplicación en un sistema agrícola campesino en la región Purhépecha, México. Documento de Trabajo D35. Grupo Interdisciplinario de Tecnología Rural Apropiada, 2000.

BIANCHI, V. L. T. et al. Agroecossistemas e meio ambiente: a necessidade da sustentabilidade. Sciencia Agrária Paranaensis. V. 05, nº 02, p. 57-62. 2006.

CHARLTON, R. Fundamentals of fluvial geomorphology. Nova Iorque: Taylor \& Francis Library, 2008.

CODEVASF. Companhia de desenvolvimento dos Vales do São Francisco e Parnaíba. Diagnóstico Situacional dos

Perímetros Irrigado da Codevasf. 2010. 
CODEVASF. Companhia de desenvolvimento dos Vales do São Francisco e Parnaíba. Mais Irrigação: projetos da Codevasf somam mais de 350 mil hectares e investimentos de $\mathrm{R} \$ 1,6$ bi. Disponível em:

http://www.codevasf.gov.br/noticias/2007/mais-irrigacao-projetos-da-codevasf-somam-mais-de-350-mil-hectares-e-

investimentos-de-r-1-6-bi/. Acesso em 22 de março de 2014.

CONWAY, R. Gordon. Agroecosystem Analysis. Agricultural Ecosystems Environment. Imperial College of Science and Technology, London, United Kingdom, ICCET. Series E, No 1 (1983).

The Properties of Agroecosystems. Agricultural Systems. 24:95-117.1987.

CUNHA, Cleidinilson de J. Regularização da vazão e sustentabilidade de agroecossistemas no estuário do rio São Francisco. Tese de Doutorado, UECE, 2015.

CUNHA, Cleidinilson de Jesus. HOLANDA, Francisco Sandro R. Estrutura, função e propriedades de agroecossistemas: Um estudo de caso no estuário do rio São Francisco. III Congresso Brasileiro de Sistemas. Florianópolis: Universidade Federal de Santa Catarina, 2007. p. 1-22.

CUNHA, Sandra B. Impactos geomorfológicos da barragem de Xingó - Baixo curso do São Francisco. In: SANTOS. Milton e BECKER, Bertha (Org.). Território, territórios: ensaios sobre o ordenamento territorial. $3^{\text {a }}$ ed. Lamparina, Rio de Janeiro, 2011, p. 352-374.

D'AGOSTINI, Luiz Renato. SCHLINDWEIN, Sandro Luis. Sobre o conceito de agroecossistema. Florianópolis, UFSCCCA. 1999.

FONTES, L. C. S. Erosão marginal no Baixo São Francisco: Um estudo de caso de impactos geomorfológicos a jusante de grandes barragens. Dissertação de Mestrado, UFS, 2002.

GLIESSMAN, Stephen R. Agroecologia: processos ecológicos em agricultura sustentável. 2ª edição. Porto Alegre: EdUFRGS, 2001.

GUERRA, A. J. T.; MENDONÇA, J. K. S. Erosão dos solos e a questão ambiental. In: VITTE, A. C.; GUERRA, A. J. T. Reflexões sobre a geografia física no Brasil. 2. ed. Rio de Janeiro: Bertrand Brasil, 2011, p. 225-256.

HART, Robert D. Conceptos básicos sobre agroecosistemas. Centro Agronómico Tropical de Investigación y Enseñanza. Turrialba, Costa Rica. 1985.

MARTEN, G. C. Produtivity, Stability, Sustainability, Equitibability and Autonomy as Properties for Agroecosystem. Assessment. Agricultural Systems. 26:291-316.1988.

OLIVEIRA et al. A constituição dos sistemas agrários - um estudo comparativo no RS. V Encontro de Grupos de Pesquisa (Agricultura, desenvolvimento regional e transformações espaciais). UFSM, 2009.

OLIVEIRA, A. M. Estudo Hidrodinâmico-Sedimentológico do Baixo São Francisco, Estuário e Zona Costeira Adjacente (AL/SE). Projeto GEF São Francisco (ANA/ GEF/ PNUMA /OEA). UFAL, 2003. 81 p. (Relatório Final).

SILVA, Wilson Francisco et al. Quantificação preliminar do aporte de sedimentos no Baixo São Francisco e seus principais impactos. X Simpósio de Recursos Hídricos do Nordeste. Fortaleza, 2010. 